\title{
Clinical and molecular investigation of a canine distemper outbreak and vector-borne infections in a group of rescue dogs imported from Hungary to Switzerland
}

Barbara Willi ${ }^{1,3^{*}}$, Andrea M. Spiri ${ }^{1,2}$, Marina L. Meli ${ }^{1,2}$, Felix Grimm ${ }^{4}$, Laura Beatrice ${ }^{3}$, Barbara Riond ${ }^{1}$, Tim Bley ${ }^{6}$, Rolf Jordi ${ }^{7}$, Matthias Dennler ${ }^{5}$ and Regina Hofmann-Lehmann ${ }^{1,2}$

\begin{abstract}
Background: Canine distemper virus (CDV) is a major pathogen of dogs and wild carnivores worldwide. In Switzerland, distemper in domestic dogs is rarely reported. In recent years, the import of dogs from Eastern Europe to Switzerland has steadily increased. In the present study, we describe a distemper outbreak in 15 rescue dogs that were imported from Hungary to Switzerland by an animal welfare organisation. The data on vaccination and medical history were recorded (14 dogs), and the samples were collected to investigate CDV and vector-borne infections (13 dogs) and canine parvovirus infection (12 dogs). The dogs were monitored for six months.

Results: One dog was euthanised directly after import. Thirteen dogs showed clinical signs after arrival, i.e., diarrhoea (57\%), coughing (43\%) and nasal and/or ocular discharge (21\%); radiographic findings that were compatible with bronchopneumonia were present in four dogs. CDV infection was diagnosed in 11 dogs (85\%); 10 dogs (91\%) tested PCR-positive in conjunctival swabs. Vector-borne infections (Babesia spp., Leishmania infantum, Dirofilaria immitis) were found in 4 dogs (31\%). Three dogs were hospitalized, and six dogs received ambulatory therapy for up to two months until recovery. None of the dogs developed neurological disease. CDV shedding was detected for a period of up to four months. Because dogs were put under strict quarantine until CDV shedding ceased, CDV did not spread to any other dogs. The CDV isolates showed $99 \%$ sequence identity in the HA gene among each other and belonged to the Arctic-like lineage of CDV.
\end{abstract}

Conclusions: The present study highlights the imminent risks of spreading contagious viral and vector-borne infections through the non-selective import of sick dogs and dogs with incomplete vaccination from Eastern Europe. CDV shedding was detected for several months after the cessation of clinical signs, which emphasised the roles of asymptomatic carriers in CDV epidemiology. A long-term follow-up using sensitive PCR and strict quarantine measures is of upmost importance in preventing the spread of infection. Dog owners and animal welfare organisations should be educated regarding the importance of complete vaccinations and the impact of dog imports on the spread of viral and vector-borne pathogens.

Keywords: Canine distemper virus, Outbreak, Domestic dog, Import, Vector-borne infections, Phylogenetic analysis, Vaccination, Arctic-like lineage

\footnotetext{
* Correspondence: bwilli@vetclinics.uzh.ch

${ }^{1}$ Clinical Laboratory, Vetsuisse Faculty, University of Zurich, Zurich,

Switzerland

${ }^{3}$ Clinic for Small Animal Internal Medicine, Vetsuisse Faculty, University of

Zurich, Zurich, Switzerland

Full list of author information is available at the end of the article
}

(c) 2015 Willi et al. This is an Open Access article distributed under the terms of the Creative Commons Attribution License (http://creativecommons.org/licenses/by/4.0), which permits unrestricted use, distribution, and reproduction in any medium, provided the original work is properly credited. The Creative Commons Public Domain Dedication waiver (http:// creativecommons.org/publicdomain/zero/1.0/) applies to the data made available in this article, unless otherwise stated. 


\section{Background}

Canine distemper virus (CDV) is one of the most important viral pathogens in domestic dogs and causes high morbidity and mortality worldwide, particularly in unvaccinated dogs or dogs with incomplete vaccination [1]. CDV is a small, enveloped RNA virus that belongs to the family Paramyxoviridae and the genus Morbillivirus [2]. CDV has a wide natural host range that includes a variety of terrestrial carnivores [2]. Dogs are thought to be the major reservoir host for CDV [3, 4]. Infection occurs by direct contact with oronasal secretions of infected animals [5]; indirect transmission plays only a minor role in CDV epidemics because the virus is quickly inactivated in the environment [6].

The course of the CDV infection is strongly dependent on the immune response in infected animals [7]. In this context, vaccination is critically important. Dogs that develop an adequate immune response can clear the virus from most tissues, whereas in dogs that show an intermediate immune response, CDV infects the epithelial tissues and induces clinical signs. In dogs that have a weak immune response, CDV disseminates to various tissues, and the clinical signs are usually severe with the persistence of the virus until death [8]. Invasion of the central nervous system occurs when viraemia is sufficiently high $[9,10]$. More than $50 \%$ of all CDV infections are perceived to be subclinical [11]. In clinically affected dogs, the disease usually starts with fever and a serous-to-mucopurulent conjunctivitis, followed by a dry to productive cough, depression, anorexia, vomiting and diarrhoea [1]. Neurological signs usually develop within one to three weeks after recovery from systemic illness, but can occur weeks to months later [12].

Since the introduction of highly protective CDV modified live virus (MLV) vaccines more than 60 years ago [13], the incidence of CDV infection in completely vaccinated dogs has decreased [8]. However, in regions with a low proportion of vaccinated dogs, in stray dogs and in shelter environments, the incidence of CDV epidemics is high. In Switzerland, the last CDV epidemic in domestic dogs occurred in 19841985; this outbreak was suspected to be attributed to an inadequate vaccination rate in the Swiss dog population at that time [14]. Furthermore, a CDV epidemic associated with high morbidity and mortality commenced in the spring of 2009 in wild carnivores in Switzerland [15]. The latter was perceived to be part of a large transnational outbreak that spread from Eastern to Western Europe. Only one domestic dog was affected in Switzerland during this outbreak [15]. Remarkably, the 2-year-old mixed breed dog died of a CDV-associated neurological disease, although it had received the standard anti-CDV vaccination protocol.
According to the Animal Identity Service (ANIS) in Switzerland, the import of dogs increased by $23 \%$ within one year (2011-2012) [16]. The imported dogs comprised primarily stray dogs that were adopted by animal welfare organizations or pure breed dogs to meet the increasing demand of miniature breeds in Western Europe. In the present study, we report on a distemper outbreak in rescue dogs that had been imported from Hungary to Switzerland. The study provides data on vaccination, medical history, clinical examinations and diagnostic imaging of the dogs and CDV testing, testing for canine parvovirus (CPV) and vector-borne infections. Additionally, the study gives prospectively collected follow-up data on the treatment, clinical course and outcome of the infections and the period of CDV shedding. Finally, a molecular characterization of the CDV isolates was performed.

\section{Results}

\section{Import and clinical history of the dogs}

A group of 15 rescue dogs that derived from a shelter in Kecskemét, Hungary, was imported to Switzerland in October 2013. One dog was euthanised within several days of import because of clinical deterioration; no data regarding this dog were available. The other 14 dogs comprised nine female (5 spayed) and five male (4 castrated) mixed breed dogs, aged 6 months to 8 years old, and weighing $5 \mathrm{~kg}$ to $30 \mathrm{~kg}$ (Table 1). All of the dogs had received rabies vaccination (Rabisin ${ }^{\odot}$, Biokema SA, Crissier, Switzerland) six to 33 weeks before import and deworming (containing Praziquantel, Pyrantel and Fenbendazol, Uniwerm ${ }^{\odot}$, PROVET, Beograd, Serbia) seven to nine days before their arrival in Switzerland. Additionally, the dogs had been vaccinated with one shot of a combined MLV vaccine containing CDV, Canine Adenovirus-2, CPV, Leptospira spp. and canine Parainfluenzavirus (Biocan ${ }^{\bullet}$ DHPPi \& L, Table 1), either seven to eight days (Dogs 1 to 6 and 8 to 14) or one month prior to arrival in Switzerland (Dog 7); Dog 12 had been revaccinated in Switzerland one week prior to sample collection for CDV PCR (Table 1). After arrival on October 22, 2013, the rescue dogs were directly distributed to 14 private households throughout Switzerland (Table 1, Fig. 1). Seven dogs (Dogs 3, 6, 7, 8, 9, 13 and 14) were placed in multidog households. After arrival, the new owners observed clinical signs in 13 of the 14 dogs (Table 1), i.e., diarrhoea (57\%), coughing (43\%), nasal and/or ocular discharge (21\%), vomiting (14\%), gagging (14\%), lameness (14\%), apathy and sneezing (each $7 \%$ ). Because of these symptoms, five dogs (Dogs 1, 2, 3, 4 and 8) were presented to private veterinarians within one week of arrival. Three of these dogs (Dogs 1, 2 and 3) were subsequently referred to small animal clinics for additional investigations. 
Table 1 Signalment, vaccination history, anamnesis, clinical examination and therapy of the 14 rescue dogs

\begin{tabular}{|c|c|c|c|c|c|c|c|c|c|}
\hline$\overline{\operatorname{Dog}^{1}}$ & Town $^{2}$ & Gender $^{3}$ & $\mathrm{Age}^{4}$ & Breed & $\begin{array}{l}\text { CDV } \\
\text { vaccination }\end{array}$ & $\begin{array}{l}\text { Symptoms after } \\
\text { arrival (22.10.13) }\end{array}$ & Date of $\mathrm{CE}^{7}$ & Findings at $\mathrm{CE}^{7}$ & Therapy $^{8}$ \\
\hline Dog 1 & Aesch & fs & $2 y$ & Mixed breed & $15.10 .13^{5}$ & Diarrhoea & 28.10 .13 & $\begin{array}{l}\text { Fever, ocular/nasal discharge, } \\
\text { coughing, tachypnoea }\end{array}$ & $\begin{array}{l}\text { Infusion, amoxicillin/clavulanic } \\
\text { acid (iv, po), inhalation }\end{array}$ \\
\hline Dog 2 & Widnau & $f$ & $8 \mathrm{~m}$ & Mixed breed & $15.10 .13^{5}$ & $\begin{array}{l}\text { Diarrhoea, coughing, } \\
\text { ocular/nasal discharge }\end{array}$ & 5.11 .13 & $\begin{array}{l}\text { Fever, ocular/nasal discharge, } \\
\text { coughing, dehydration, } \\
\text { increased inspiratory lung } \\
\text { sounds, fluid-filled bowel } \\
\text { loops }\end{array}$ & $\begin{array}{l}\text { Amoxicillin/clavulanic acid (po), } \\
\text { tobramycin eye drops }\end{array}$ \\
\hline Dog 3 & Hettiswil & fs & $2 y$ & Mixed breed & $15.10 .13^{5}$ & $\begin{array}{l}\text { Apathy, coughing, } \\
\text { nasal discharge }\end{array}$ & 22.10 .13 & $\begin{array}{l}\text { Fever, paleness, purulent- } \\
\text { bloody nasal discharge, } \\
\text { increased inspiratory lung } \\
\text { sounds, diarrhoea }\end{array}$ & $\begin{array}{l}\text { Infusion, amoxicillin/clavulanic acid } \\
\text { (iv, po), marbofloxacine (iv, po), } \\
\text { imidocarb diproprionate (sc) }\end{array}$ \\
\hline Dog 4 & Niederglatt & $\mathrm{mc}$ & $3 y$ & Mixed breed & $15.10 .13^{5}$ & $\begin{array}{l}\text { Diarrhoea, coughing, } \\
\text { gagging }\end{array}$ & 22.10 .13 & $\begin{array}{l}\text { Fever, purulent ocular } \\
\text { discharge, coughing, increased } \\
\text { inspiratory lung sounds, } \\
\text { conjunctivitis }\end{array}$ & $\begin{array}{l}\text { Infusion, amoxicillin/ } \\
\text { clavulanic acid (iv, po), } \\
\text { allopurinol, inhalation }\end{array}$ \\
\hline Dog 5 & Aadorf & $\mathrm{m}$ & $6 \mathrm{~m}$ & Mixed breed & $15.10 .13^{5}$ & None & 5.11 .13 & Fluid-filled bowel loops & $\begin{array}{l}\text { Amoxicillin/clavulanic acid } \\
(p o) \text {, metronidazole }(p o), \\
\text { diet, deworming }\end{array}$ \\
\hline Dog 6 & Unterkulm & $f$ & $6 \mathrm{~m}$ & Mixed breed & $15.10 .13^{5}$ & Diarrhoea, sneezing & 5.11 .13 & $\begin{array}{l}\text { Conjunctivitis, fluid-filled } \\
\text { bowel loops }\end{array}$ & Amoxicillin/clavulanic acid (po) \\
\hline Dog 7 & Niedergösgen & $f$ & $7 \mathrm{~m}$ & Mixed breed & $18.09 .13^{5}$ & $\begin{array}{l}\text { Diarrhoea, coughing, } \\
\text { gagging }\end{array}$ & 5.11 .13 & $\begin{array}{l}\text { Coughing, increased inspiratory } \\
\text { lung sounds }\end{array}$ & Amoxicillin/clavulanic acid (po) \\
\hline Dog 8 & Urtenen-Schönbühl & f & $8 y$ & Mixed breed & $14.10 .13^{5}$ & Coughing, lameness & 23.10 .13 & $\begin{array}{l}\text { Paleness, cachexia, otitis } \\
\text { externa }\end{array}$ & $\begin{array}{l}\text { Doxycycline (po), ear drops } \\
\left(\text { Aurizon }^{\oplus)} \text {, imidocarb }\right. \\
\text { diproprionate (sc) }\end{array}$ \\
\hline Dog 9 & Biel & fs & $1 y$ & Mixed breed & $15.10 .13^{5}$ & Vomiting & 6.11 .13 & Mucous vaginal discharge & Unknown \\
\hline Dog 10 & Rheinsulz & $\mathrm{mc}$ & $3 y$ & Mixed breed & $14.10 .13^{5}$ & $\begin{array}{l}\text { Diarrhoea, nasal } \\
\text { discharge }\end{array}$ & 7.11 .13 & $\begin{array}{l}\text { Conjunctivitis, purulent/ } \\
\text { mucous ocular/nasal } \\
\text { discharge }\end{array}$ & Doxycycline (po) \\
\hline Dog 11 & Zullwil & fs & $2 y$ & Mixed breed & $15.10 .13^{5}$ & Lameness & 6.11 .13 & Lameness & None \\
\hline Dog 12 & Küsnacht & fs & $2 y$ & Mixed breed & $14.10 .13^{5}, 5.11 .13^{6}$ & Vomiting & 24.10 .13 & Normal & None \\
\hline Dog 13 & Meiringen & $\mathrm{mc}$ & $3 y$ & Mixed breed & $15.10 .13^{5}$ & Diarrhoea & 12.11 .13 & Normal & None \\
\hline Dog 14 & Rufi & $\mathrm{mc}$ & $2 y$ & Mixed breed & $15.10 .13^{5}$ & Diarrhoea, coughing & - & - & Antibiotic injection ${ }^{9}$ (sc) \\
\hline
\end{tabular}

${ }^{1} \mathrm{CDV}$ positive dogs (at first presentation) are shown in bold, no clinical examination could be performed in Dog 14 due to aggressive behaviour; ${ }^{2}$ see also Fig. $1 ;{ }^{3} \mathrm{~m}$ male intact, $m c$ male castrated, $f$ female intact, $f s$ female spayed; ${ }^{4}$ y year, $m$ month(s); ${ }^{5}$ vaccination with Biocan DHPPi \& L; ${ }^{6}$ vaccination with Nobivac DHPPi; ${ }^{7} C E$ clinical examination; ${ }^{8}$ po per os, iv intravenous, sC subcutaneously; ${ }^{9}$ the antibiotic compound used in Dog 14 was unknown 


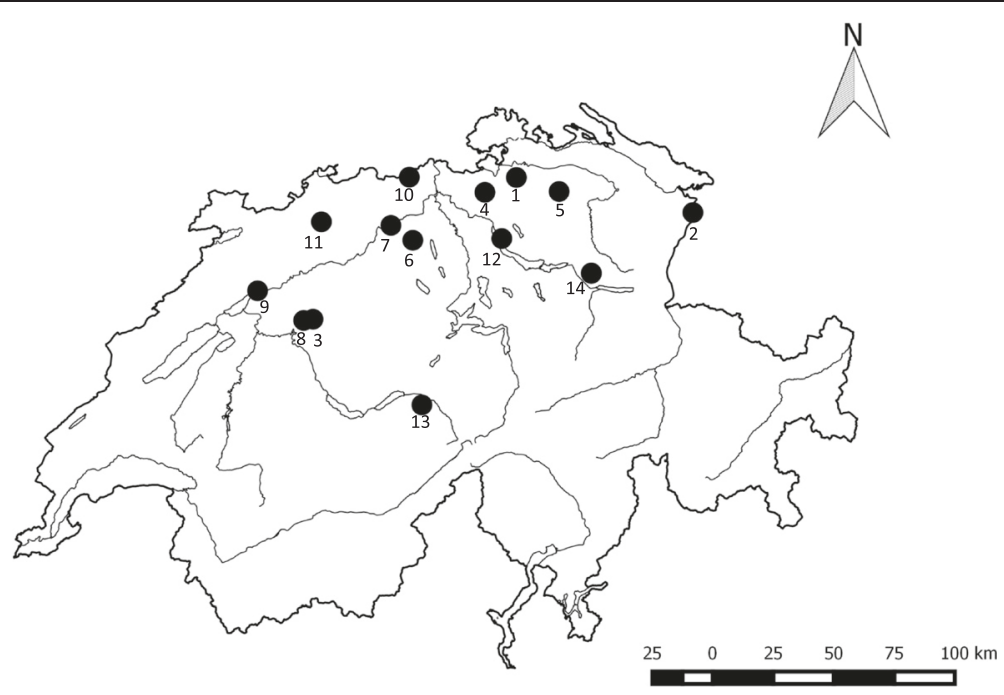

Fig. 1 Map of Switzerland showing the geographical distribution of the rescue dogs. Numbers 1 to 14 indicate the location of the 14 dogs (see also Table 1)

\section{Clinical examination findings}

Clinical examinations were performed on Dogs 1 to 13 (Table 1); Dog 14 could not be examined because of aggressive behaviour. The clinical examinations revealed mucous, purulent or bloody ocular and/or nasal discharge (39\%), fever (31\%), coughing (31\%), inspiratory increased lung sounds (31\%), conjunctivitis (23\%), fluid-filled bowel loops (23\%), paleness (15\%), and lameness, tachypnoea, diarrhoea, dehydration, cachexia, otitis externa and vaginal discharge in single dogs (Table 1). The clinical examinations were unremarkable in Dogs 12 and 13.

\section{Haematology and blood biochemistry}

Haematology and blood biochemistry results were available for 13 dogs (Tables 2 and 3), 11 of which were CDV-PCR positive (Dogs 1 to 11, see below). At initial presentation, anaemia $(9 / 13,69 \%)$, leucocytosis $(8 / 13$, $62 \%)$, eosinophilia (8/11, $73 \%)$, neutrophilia (6/11, $55 \%)$ and monocytosis (5/12, $42 \%)$ were common (Table 2). Dogs 3 and 4 showed severe pancytopenia and moderate bicytopenia, respectively; both were CDV PCR-positive, co-infected with Babesia spp. (Dog 3) or positive for anti-Leishmania infantum antibodies (Dog 4, see below), and they exhibited fever, increased inspiratory lung sounds, purulent ocular and nasal discharge and radiographic signs that were compatible with bronchopneumonia (Tables 1 to 5). Dog 8 showed slight anaemia and leucopenia (Table 2); this animal was co-infected with CDV and Babesia spp. (Tables 4 and 5). Dog 13 showed a pronounced eosinophilia (Table 2); this animal was CDV-PCR negative but Dirofilaria immitis positive (Tables 4 and 5). Blood biochemistry results revealed only unspecific changes in the dogs (Table 3 ).
Radiographic examinations and echocardiography

The radiographic examinations of the thorax revealed moderate-to-severe interstitial lung changes with variable bronchial thickening in four dogs (Dogs 1 - 4). The changes were generalised and most pronounced in the dorsal (Dog 2), perihilar (Dogs 2 and 4) and caudal lung areas (Dog 3, Fig. 2). The radiographic findings were compatible with bronchopneumonia in all four dogs, and all of the dogs tested CDV PCR-positive. The thoracic radiographs of Dog 13 revealed mild right-sided cardiomegaly and mild generalised bronchointerstitial lung changes; echocardiography showed mild tricuspid and aortic regurgitation but no signs of pulmonary hypertension or right ventricular pressure overload. Dog 13 tested D. immitis-positive but was negative for CDV.

\section{PCR and sequencing results}

Eleven of the 13 dogs tested CDV PCR-positive during the initial examination (Table 4). The positive PCR results were most commonly obtained from conjunctival swabs (10 of the $11 \mathrm{CDV}$-positive dogs, Table 4). The vaccine-specific real-time reverse transcription (RT)quantitative (q)PCR was negative for all ten dogs that were tested, which supports the finding of infection with a wild-type CDV strain. All three vaccines that were tested (Biocan ${ }^{\circ}$ DHPPi \& L, Bioveta, Ivanovice na Hané, Czech Republic; Nobivac ${ }^{\circ}$ DHHPi, MSD Animal Health, Luzern, Switzerland; Canigen ${ }^{\circ}$ SHA2PPi, Vibac, Glattbrugg, Switzerland) exhibited a positive PCR result. In gel electrophoresis of the PCR products, a appropriate-sized band was detected for all ten dogs, as were the three vaccines, as expected [17]. The sequence of the amplification product of the Biocan ${ }^{\bullet}$ DHPPi \& L vaccine used in the dogs of the present study was clearly distinct from the sequence 
Table 2 Haematology results of 13 rescue dogs at first presentation

\begin{tabular}{|c|c|c|c|c|c|c|c|c|c|c|}
\hline$\overline{\operatorname{Dog}^{1}}$ & Date & $P C V^{2}\left(\operatorname{Ref}^{3}\right) \%$ & $\begin{array}{l}\operatorname{Leuc}^{4}\left(\operatorname{Ref}^{3}\right) \times \\
10^{3} / \mu 1\end{array}$ & $\begin{array}{l}\operatorname{Plat}^{5}\left(\operatorname{Ref}^{3}\right) \times \\
10^{3} / \mu l\end{array}$ & $\begin{array}{l}\text { Band Neutro }{ }^{6}\left(\operatorname{Ref}^{3}\right) \times \\
10^{3} / \mu \mathrm{l}\end{array}$ & $\begin{array}{l}\text { Segm Neutro }{ }^{7}\left(\operatorname{Ref}^{3}\right) \times \\
10^{3} / \mu l\end{array}$ & $\begin{array}{l}\operatorname{Lymph}^{8}\left(\operatorname{Ref}^{3}\right) \times \\
10^{3} / \mu \mathrm{l}\end{array}$ & $\begin{array}{l}\text { Mono }^{9}\left(\operatorname{Ref}^{3}\right) \times \\
10^{3} / \mu l\end{array}$ & $\begin{array}{l}\operatorname{Eos}^{10}\left(\operatorname{Ref}^{3}\right) \times \\
10^{3} / \mu 1\end{array}$ & $\begin{array}{l}\text { Baso }^{11}\left(\operatorname{Ref}^{3}\right) \times \\
10^{3} / \mu l\end{array}$ \\
\hline $\operatorname{Dog} 1$ & 28.10 .13 & $32(42-55)$ & $5.6(4.7-11.3)$ & $131(130-394)$ & $0.06(-0.08)$ & $4.11(2.5-7.4)$ & $\mathbf{1 . 0 7}(1.2-3.4)$ & $0.37(0.2-0.9)$ & $\mathbf{0 . 0 3}(0.1-1.3)$ & $0(-0.08)$ \\
\hline $\operatorname{Dog} 2$ & 5.11 .13 & $34(42-55)$ & $11.8(4.7-11.3)$ & $157(130-394)$ & $0(-0.08)$ & $8.7(2.5-7.4)$ & $\mathbf{0 . 7}(1.2-3.4)$ & $0.78(0.2-0.9)$ & $1.57(0.1-1.3)$ & $0.02(-0.08)$ \\
\hline $\operatorname{Dog} 3$ & 23.10 .13 & $28(39-57)$ & $1.03(6.0-12.0)$ & $17(150-400)$ & $\mathbf{0 . 3 3}(-0.3)$ & $\mathbf{0 . 2 5}(3.0-11.5)$ & $\mathbf{0 . 2 8}(1.0-4.8)$ & $0.17(0.15-1.4)$ & $\mathbf{0}(0.1-1.3)$ & $0(-0.04)$ \\
\hline Dog 4 & 22.10 .13 & $36(42-57)$ & $9.9(5.7-12.4)$ & $88(200-400)$ & & & & & & \\
\hline Dog 5 & 5.11 .13 & $33(42-55)$ & $17.9(4.7-11.3)$ & 341 (130-394) & $0(-0.08)$ & $13.1(2.5-7.4)$ & $1.67(1.2-3.4)$ & $1.43(0.2-0.9)$ & $1.64(0.1-1.3)$ & $0.05(-0.08)$ \\
\hline Dog 6 & 5.11 .13 & $36(42-55)$ & $13.2(4.7-11.3)$ & $131(130-394)$ & $0(-0.08)$ & $9.23(2.5-7.4)$ & $2.31(1.2-3.4)$ & $1.1(0.2-0.9)$ & $0.51(0.1-1.3)$ & $0.05(-0.08)$ \\
\hline Dog 7 & 5.11 .13 & $45(42-55)$ & $14.3(4.7-11.3)$ & 430 (130-394) & $0(-0.08)$ & $7.84(2.5-7.4)$ & $2.03(1.2-3.4)$ & $1.36(0.2-0.9)$ & $2.89(0.1-1.3)$ & $\mathbf{0 . 1 3}(-0.08)$ \\
\hline Dog 8 & 23.10 .13 & $33(37-55)$ & $5.44(6.0-17.0)$ & $619(150-500)$ & & & $\mathbf{0 . 5}(1.0-4.8)$ & $0.1(0.1-1.8)$ & & \\
\hline Dog 9 & 6.11 .13 & $42(42-55)$ & $18.1(4.7-11.3)$ & $146(130-394)$ & $0(-0.08)$ & $12.61(2.5-7.4)$ & $2.09(1.2-3.4)$ & $1.33(0.2-0.9)$ & $1.96(0.1-1.3)$ & $0.06(-0.08)$ \\
\hline Dog 10 & 7.11 .13 & $31(42-55)$ & $9.9(4.7-11.3)$ & $418(130-394)$ & $0(-0.08)$ & $3.68(2.5-7.4)$ & $1.77(1.2-3.4)$ & $1.19(0.2-0.9)$ & $3.21(0.1-1.3)$ & $0.06(-0.08)$ \\
\hline Dog 11 & 6.11 .13 & $42(42-55)$ & $13.4(4.7-11.3)$ & $231(130-394)$ & $0(-0.08)$ & $6.06(2.5-7.4)$ & $4.75(1.2-3.4)$ & $0.85(0.2-0.9)$ & $1.62(0.1-1.3)$ & $\mathbf{0 . 1 3}(-0.08)$ \\
\hline Dog 12 & 24.10 .13 & $46(38-55)$ & $19.0(6.0-12.0)$ & $159(150-500)$ & & $10.17(3.0-10.0)$ & $7.24(1.0-4.0)$ & $0.61(0-1.2)$ & $0.95(0-0.6)$ & $0.04(-0.04)$ \\
\hline Dog 13 & 12.11 .13 & $38(42-55)$ & $11.4(4.7-11.3)$ & $250(130-394)$ & $0.06(0-0.08)$ & $2.23(2.5-7.4)$ & $2.4(1.2-3.4)$ & $0.51(0.2-0.9)$ & $6.11(0.1-1.3)$ & $\mathbf{0 . 1 1}(-0.08)$ \\
\hline \multirow{2}{*}{$\begin{array}{l}\text { Total } \\
(\%)\end{array}$} & Increased & & $8 / 13(62 \%)$ & $3 / 13(23 \%)$ & $1 / 10(10 \%)$ & $6 / 11(55 \%)$ & $2 / 12(17 \%)$ & $5 / 12(42 \%)$ & $8 / 11(73 \%)$ & $3 / 11$ (27 \%) \\
\hline & Decreased & 9/13 (69\%) & $2 / 13(15 \%)$ & $2 / 13$ (15\%) & & $2 / 11$ (18 \%) & 4/12 (33 \%) & & 2/11 (18 \%) & \\
\hline
\end{tabular}

Values outside the reference range are shown in bold

${ }^{1} \mathrm{CDV}$ positive dogs (at first presentation) are shown in bold, no samples could be collected from Dog 14 (not shown) due to aggressive behaviour; ${ }^{2} P C V$ packed cell volume; ${ }^{3}$ Reference range; ${ }^{4}$ Leuc leucocytes; ${ }^{5}$ Plat platelets; ${ }^{6}$ Band Neutro banded neutrophils; ${ }^{7}$ Segm Neutro segmented neutrophils; ${ }^{8}$ Lymph lymphocytes; ${ }^{9}$ Mono monocytes; ${ }^{10}$ Eos eosinophils; ${ }^{11}$ Baso basophils 
Table 3 Blood biochemistry results of 13 rescue dogs at first presentation

\begin{tabular}{|c|c|c|c|c|c|c|c|c|c|c|c|}
\hline$\overline{\operatorname{Dog}^{1}}$ & Date & $\begin{array}{l}\mathrm{Bil}^{2}\left(\operatorname{Ref}^{3}\right) \\
\mu \mathrm{mol} / / \mathrm{l}\end{array}$ & Urea $\left(\operatorname{Ref}^{3}\right) \mathrm{mmol} / \mathrm{l}$ & $\operatorname{Crea}^{4}\left(\operatorname{Ref}^{3}\right) \mu \mathrm{mol} / \mathrm{l}$ & $\mathrm{TP}^{5}\left(\operatorname{Ref}^{3}\right) \mathrm{g} / \mathrm{l}$ & $\mathrm{Alb}^{6}\left(\operatorname{Ref}^{3}\right) \mathrm{g} / \mathrm{l}$ & $A P^{7}\left(\operatorname{Ref}^{3}\right) \cup / l$ & $\mathrm{ALAT}^{8}\left(\operatorname{Ref}^{3}\right) \mathrm{U} / \mathrm{I}$ & $\mathrm{Na}^{9}\left(\operatorname{Ref}^{3}\right) \mathrm{mmol} / \mathrm{l}$ & $\mathrm{K}^{10}\left(\operatorname{Ref}^{3}\right) \mathrm{mmol} / \mathrm{l}$ & $\mathrm{P}^{11}\left(\operatorname{Ref}^{3}\right) \mathrm{mmol} / \mathrm{l}$ \\
\hline $\operatorname{Dog} 1$ & 28.10 .13 & $0.6(-3.5)$ & $4.4(3.8-5.9)$ & $50(50-119)$ & $57(56-71)$ & $30(29-37)$ & $25(20-98)$ & $23(20-93)$ & 152 (152-159) & $4.3(4.3-5.3)$ & $1.13(1-1.6)$ \\
\hline Dog 2 & 5.11 .13 & $0.6(-3.5)$ & $2.6(1.6-6.2)$ & $44(19-79)$ & $58(56-71)$ & $29(29-37)$ & $38(4-252)$ & $28(20-93)$ & $153(152-159)$ & $4.6(4.3-5.3)$ & $1.89(1.1-2.5)$ \\
\hline Dog 3 & 23.10 .13 & $2.5(-3.9)$ & $3.4(3.3-10.8)$ & $44(52-177)$ & $56(56-73)$ & $20(30-41)$ & $225(9-132)$ & $18(26-126)$ & $141(142-154)$ & $4.5(4.2-5.4)$ & $0.55(0.9-1.9)$ \\
\hline Dog 4 & 22.10 .13 & $1.7(-6.8)$ & $3.8(2.5-8.8)$ & $84(-133)$ & $58(54-68)$ & $31(30-37)$ & $297(-240)$ & $63(0-75)$ & $146(140-155)$ & $4.7(3.9-5.4)$ & $1.1(1.0-1.7)$ \\
\hline Dog 5 & 5.11 .13 & $0.2(-3.5)$ & $2.9(1.6-6.2)$ & $41(19-79)$ & $49(56-71)$ & $21(29-37)$ & $115(4-252)$ & $24(20-93)$ & $150(152-159)$ & $\mathbf{5 . 7}(4.3-5.3)$ & $2.6(1.1-2.5)$ \\
\hline Dog 6 & 5.11 .13 & $1.1(-3.5)$ & $4.2(1.6-6.2)$ & $57(19-79)$ & $49(56-71)$ & $27(29-37)$ & $132(4-252)$ & 29 (20-93) & $151(152-159)$ & $4.7(4.3-5.3)$ & $1.75(1.1-2.5)$ \\
\hline $\operatorname{Dog} 7$ & 5.11 .13 & $0.2(-3.5)$ & $2.3(1.6-6.2)$ & $45(19-79)$ & $54(56-71)$ & $27(29-37)$ & $94(4-252)$ & $36(20-93)$ & $152(152-159)$ & $5.1(4.3-5.3)$ & $1.93(1.1-2.5)$ \\
\hline Dog 8 & 23.10 .13 & $7.0(-10)$ & $7.0(2.5-8.9)$ & $94(27-124)$ & $73(54-82)$ & $33(25-44)$ & $108(20-150)$ & $46(10-118)$ & $143(138-160)$ & $5.9(3.7-5.8)$ & $1.84(0.9-2.1)$ \\
\hline Dog 9 & 6.11 .13 & $1.3(-3.5)$ & $5.6(3.8-5.9)$ & $84(50-119)$ & $60(56-71)$ & $34(29-37)$ & 35 (20-98) & $29(20-93)$ & $154(152-159)$ & $4.8(4.3-5.3)$ & $1.6(1-1.6)$ \\
\hline Dog 10 & 7.11 .13 & $0.3(-3.5)$ & $2.9(3.8-5.9)$ & $58(50-119)$ & $64(56-71)$ & $26(29-37)$ & 60 (20-98) & $26(20-93)$ & $153(152-159)$ & $5.0(4.3-5.3)$ & $1.8(1-1.6)$ \\
\hline Dog 11 & 6.11 .13 & $1.4(-3.5)$ & $6.7(3.8-5.9)$ & $69(50-119)$ & $62(56-71)$ & $35(29-37)$ & 40 (20-98) & 23 (20-93) & $152(152-159)$ & $5.4(4.3-5.3)$ & $1.92(1-1.6)$ \\
\hline Dog 12 & 24.10 .13 & $2.5(-5.4)$ & $6.2(2.8-10.7)$ & $103(-133)$ & $64(52-71)$ & $30(26-37)$ & $138(0-121)$ & $79(-115)$ & $151(143-152)$ & $4.7(3.9-5.4)$ & $1.4(0.9-2)$ \\
\hline Dog 13 & 12.11 .13 & $1.6(-3.5)$ & $4.3(3.8-5.9)$ & $101(50-119)$ & $59(56-71)$ & $31(29-37)$ & $34(20-98)$ & 31 (20-93) & $152(152-159)$ & $4.7(4.3-5.3)$ & $1.8(1-1.6)$ \\
\hline \multirow[t]{2}{*}{ Total (\%) } & Increased & & $1 / 13(8 \%)$ & & & & $3 / 13(23 \%)$ & & & $3 / 13(23 \%)$ & 4/13 (31 \%) \\
\hline & Decreased & & $1 / 13(8 \%)$ & & $3 / 13(23 \%)$ & 5/13 (39 \%) & & 1/13 (8 \%) & $3 / 13(23 \%)$ & & $1 / 13(8 \%)$ \\
\hline
\end{tabular}

Values outside the reference range are shown in bold

"CDV positive dogs (at first presentation) are shown in bold no samples could be collected from Dog 14 (not shown)

${ }^{6} \mathrm{Alb}$ albumin; ${ }^{7} \mathrm{AP}$ alkaline phosphatase; ${ }^{8} \mathrm{ALAT}$ alanine aminotransferase; ${ }^{9} \mathrm{Na}$ sodium; ${ }^{10} \mathrm{~K}$ potassium; ${ }^{11} P$ phosphorus 
Table 4 CDV PCR results at first presentation and at different time points thereafter in 13 rescue dogs

\begin{tabular}{|c|c|c|c|c|c|c|c|c|c|c|c|c|c|c|c|c|c|}
\hline \multirow[t]{3}{*}{$\operatorname{Dogs}^{1}$} & \multirow{3}{*}{$\begin{array}{l}\text { Date of first } \\
\text { investigation }\end{array}$} & \multicolumn{16}{|c|}{ CDV real-time $R T-q P C R$ results ${ }^{2}$} \\
\hline & & \multicolumn{3}{|c|}{ At first investigation } & \multirow{2}{*}{$\begin{array}{l}\text { After } 1 \text { month } \\
\text { CS/NS/OC }\end{array}$} & \multicolumn{3}{|c|}{ After 2 months } & \multicolumn{3}{|c|}{ After 3 months } & \multicolumn{3}{|c|}{ After 4 months } & \multicolumn{3}{|c|}{ After 5 months } \\
\hline & & $\overline{C S}$ & NS & Blood & & $\mathrm{CS}$ & NS & $O C$ & $\overline{C S}$ & NS & $O C$ & $\mathrm{CS}$ & NS & $O C$ & $\overline{C S}$ & NS & OC \\
\hline $\operatorname{Dog} 1$ & 28.10 .13 & pos & & pos & pos & & & & pos & pos & neg & pos & pos & neg & neg & neg & $\overline{\text { neg }}$ \\
\hline $\operatorname{Dog} 2$ & 5.11 .13 & pos & pos & pos & pos & & & & neg & pos & neg & neg & pos & neg & neg & neg & neg \\
\hline Dog 3 & $6.11 .13^{3}$ & pos & neg & pos & pos & & & & neg & neg & neg & & & & & & \\
\hline Dog 4 & 22.10 .13 & pos & & & & & & & & & & & & & & & \\
\hline Dog 5 & 5.11 .13 & pos & pos & pos & neg & & & & & & & & & & & & \\
\hline Dog 6 & 5.11 .13 & pos & pos & pos & pos & pos & pos & neg & pos & neg & neg & neg & neg & neg & & & \\
\hline $\operatorname{Dog} 7$ & 5.11 .13 & neg & pos & pos & quest $^{7}$ & neg & neg & neg & & & & & & & & & \\
\hline $\operatorname{Dog} 8$ & $6.11 .13^{4}$ & pos & pos & neg & pos & neg & neg & neg & & & & & & & & & \\
\hline Dog 9 & 6.11 .13 & pos & & neg & pos & neg & neg & neg & & & & & & & & & \\
\hline Dog 10 & 7.11 .13 & pos & neg & neg & pos & pos & pos & pos & pos & pos & neg & & & & & & \\
\hline Dog 11 & 6.11 .13 & pos & neg & neg & neg & & & & & & & & & & & & \\
\hline Dog 12 & $12.11 .13^{5}$ & neg & neg & & & & & & & & & & & & & & \\
\hline Dog 13 & 12.11 .13 & neg & neg & neg & & & & & & & & & & & & & \\
\hline Total positive & & $11 / 13$ & & & $7 / 10$ & $2 / 5$ & & & $4 / 5$ & & & $2 / 3$ & & & $0 / 2$ & & \\
\hline
\end{tabular}

Positive results are shown in bold

${ }^{1}$ CDV PCR-positive dogs (at first investigation) are shown in bold, no samples could be collected from Dog 14 (not shown) due to aggressive behaviour. ${ }^{2}$ CS conjunctival swab, NS nasal swab, OC oropharyngeal swab, pos positive result, neg negative result, quest questionable result. ${ }^{3}$ Dog 3 had already tested CDV PCR-positive in a CS collected at first presentation (23.10.13) by the private veterinarian. ${ }^{4}$ Samples for CDV PCR were collected for the first time two weeks after first presentation (23.10.13). ${ }^{5}$ Dog 12 had already tested CDV PCR-negative in blood collected by the private veterinarian at first presentation (24.10.13). ${ }^{6}$ Conjunctival, nasal and oropharyngeal swabs were pooled for CDV PCR. ${ }^{7} \mathrm{PCR}$ result questionable due to low cGAPDH levels (for details, see Methods section)

of the CDV isolates of the ten rescue dogs (Fig. 3) and most closely related to the CDV vaccine strain Onderstepoort (99\% nucleotide identity to AB250738).

Sequencing of the HA gene of CDV isolates of five of the infected dogs revealed that the dogs were infected with a similar CDV strain (99.9-100\% nucleotide identity among the HA gene of CDV isolates of Dogs 1, 5, 6 and 10); the HA gene of the CDV isolate of Dog 9 differed in only one nucleotide position from the HA gene sequences of the other four CDV isolates. The phylogenetic analysis revealed that the isolates from the five import dogs belonged to the Arctic-like lineage of CDV (Fig. 4). The HA gene sequences of the CDV isolates were most similar to a published HA gene sequence of a CDV strain from a domestic dog from Italy (KF914669, 99 \% nucleotide identity, Fig. 4) [18]. They were only distantly related to CDV strains isolated during a CDV epidemic in wild carnivores in Switzerland (JF810109 and JF810111, 92.6 \% nucleotide identity, Fig. 4)

\section{CDV follow-up}

Overall, two dogs (Dogs 5 and 11) exhibited CDV PCRnegative results one month after the initial examination (Table 4). Two months after the initial examination, another three dogs were found to be CDV PCR-negative
(Dogs 7 to 9); three months after the initial examination, Dog 3 was CDV-negative and the remaining three dogs tested CDV-negative four months (Dog 6) and five months (Dogs 1 and 2) after the initial examination (Table 4).

\section{Results for CPV and vector-borne infections}

All twelve dogs that were tested for CPV at the initial presentation were PCR-negative (Table 5). Vector-borne infections were detected in 4 dogs (31 \%, Table 5): infection with Babesia spp. was detected in Dogs 3 and 8; infection with $L$. infantum was diagnosed in Dog 4 and infection with Dirofilaria immitis was found in Dog 13. Dog 13, which tested positive in D. immitis antigen and Knott tests, had received a certificate from a laboratory in Budapest, Hungary, that stated a negative result in the Knott test in August 2013. None of the rescue dogs tested positive for Ehrlichia canis (Table 5).

\section{Therapy, clinical course and outcome}

The CDV-infected Dogs 1, 3 and 4 were hospitalized for two to three days and received intravenous infusions of crystalloids, intravenous antibiotic therapy and inhalation (Table 1). Dog 3, which was co-infected with Babesia spp., was treated with two imidocarb injections two weeks apart. Dog 4, which was co-infected with L. infantum was treated using allopurinol. All three dogs 
Table 5 Results for CPV and for vector-borne infections in 13 rescue dogs

\begin{tabular}{|c|c|c|c|c|c|c|}
\hline $\operatorname{Dog}^{1}$ & Date of sampling & $\mathrm{CPV}^{2,3}$ & Babesia spp. $^{2}$ & Ehrlichia canis $^{2}$ & Leishmania infantum $^{2}$ & Dirofilaria immitis $^{2}$ \\
\hline Dog 1 & 28.10 .13 & neg & neg $^{5}$ & neg $^{8}$ & neg $^{10}$ & neg $^{12}$ \\
\hline $\operatorname{Dog} 2$ & 05.11 .13 & neg & neg $^{5}$ & neg $^{8}$ & neg ${ }^{10}$ & neg $^{12}$ \\
\hline \multirow[t]{2}{*}{ Dog 3} & 25.10 .13 & & $\operatorname{pos}^{4}$ & & & \\
\hline & 06.11 .13 & neg & $\operatorname{pos}^{5}$ & neg $^{8}$ & neg ${ }^{10}$ & neg $^{12}$ \\
\hline Dog 4 & 22.10 .13 & & neg ${ }^{4}$ & neg $^{9}$ & $\operatorname{pos}^{11}$ & \\
\hline $\operatorname{Dog} 5$ & 5.11 .13 & neg & neg $^{5}$ & neg $^{8}$ & neg ${ }^{10}$ & neg $^{12}$ \\
\hline Dog 6 & 5.11 .13 & neg & neg $^{5}$ & neg $^{8}$ & neg ${ }^{10}$ & neg $^{12}$ \\
\hline $\operatorname{Dog} 7$ & 5.11 .13 & neg & neg $^{5}$ & neg $^{8}$ & neg ${ }^{10}$ & neg ${ }^{12}$ \\
\hline \multirow[t]{2}{*}{ Dog 8} & 23.10 .13 & & $\operatorname{pos}^{6}$ & & & \\
\hline & 6.11 .13 & neg & $\operatorname{pos}^{5}$ & neg $^{8}$ & interm $^{10}$ & neg $^{12}$ \\
\hline Dog 9 & 6.11 .13 & neg & neg $^{5}$ & neg $^{8}$ & neg ${ }^{10}$ & neg $^{12}$ \\
\hline Dog 10 & 7.11 .13 & neg & neg $^{5}$ & neg $^{8}$ & neg ${ }^{10}$ & neg $^{12}$ \\
\hline Dog 11 & 6.11 .13 & neg & neg $^{5}$ & neg $^{8}$ & neg ${ }^{10}$ & neg $^{12}$ \\
\hline \multirow[t]{2}{*}{ Dog 12} & 24.10 .13 & & interm $^{7}$ & neg $^{8}$ & neg ${ }^{10}$ & neg ${ }^{13}$ \\
\hline & 12.11 .13 & neg & & & & \\
\hline Dog 13 & 12.11 .13 & neg & neg $^{4}$ & neg $^{8}$ & neg ${ }^{10}$ & $\operatorname{pos}^{12,14}$ \\
\hline \multicolumn{2}{|c|}{ Total positive (\%) } & $0 / 12(0 \%)$ & 2/13 (15 \%) & $0 / 13(0 \%)$ & 1/13 (8 \%) & $1 / 13$ (8 \%) \\
\hline
\end{tabular}

Positive results are shown in bold

${ }^{1}$ CDV-positive dogs (at first presentation) are shown in bold; no samples could be collected from Dog 14 (not shown) due to aggressive behaviour; ${ }^{2}$ pos positive, neg negative, interm intermediate result, ${ }^{3}$ Result of CPV real-time qPCR; ${ }^{4}$ Microscopic evaluation of blood smears for the presence of Babesia spp. organisms by the private veterinarian (Dog 3) or a commercial laboratory (Dog 4: Alomed, Radolfzell-Böhringen, Germany); ${ }^{5}$ Commercial immunofluorescence antibody test (IFAT) for detecting anti-Babesia canis antibodies (MegaFLUO ${ }^{\oplus}$ BABESIA canis, Megacor Diagnostik GmbH, Hörbranz, Austria) performed by the Institute of Parasitology, University of Zurich; ${ }^{6}$ Babesia-specific PCR assay from blood performed by a commercial laboratory (Labor am Zugersee, Hünenberg, Switzerland); ${ }^{7}$ Enzyme-linked immunosorbent assay (ELISA) for the detection of $B$. canis antibodies performed by a commercial laboratory (IDEXX Diavet AG, Bäch, Switzerland); ${ }^{8}$ Commercial IFAT for detecting immunoglobulin G antibodies against Ehrlichia canis (Mega Screen Fluoehrlichia canis, Megacor GmbH) performed by the Clinical Laboratory, University of Zurich; ${ }^{9}$ PCR for detecting E. canis from blood performed by a commercial laboratory (Alomed); ${ }^{10}$ Published ELISA for the specific detection of anti-Leishmania IgG antibodies [45] performed by the Institute of Parasitology, University of Zurich, using Leishmania infantum promastigote stage antigens and goat anti-dog IgG ( $\gamma$ ) antibodies conjugated to alkaline phosphatase (Kirkegaard and Perry Lab, Inc., Maryland, USA); ${ }^{11}$ IFAT for detecting anti-L. infantum antibodies performed by a commercial laboratory (Alomed); ${ }^{12}$ commercial Dirofilaria immitis antigen detection test (DiroCHECK, Synbiotics, Lyon, France) performed by the Institute of Parasitology, University of Zurich; ${ }^{13} \mathrm{ELISA}$ for the detection of $D$. immitis antigen performed by a commercial laboratory (IDEXX Diavet AG); ${ }^{14}$ Knott Test for the detection of microfilaria of $D$. immitis performed by the Institute of Parasitology, University of Zurich, as previously published [46]

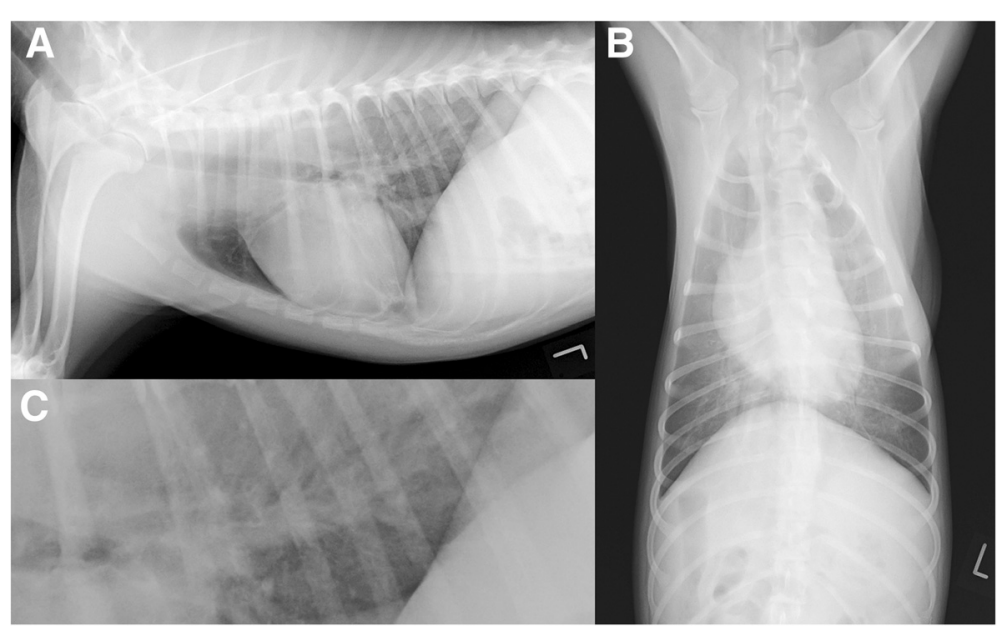

Fig 2 Diagnostic imaging of the thorax of Dog 2. a Right to left lateral, (b): ventrodorsal, and (c): close-up of the lateral projection in the caudodorsal lung field of Dog 2 showing a generalized, moderate, mildly heterogeneous increase in pulmonary opacity, numerous thickened bronchial ring shadows and reduced delineation of the peripheral pulmonary vessels. These generalized moderate broncho-interstitial lung changes are compatible with a moderate bronchopneumonia or bronchitis 


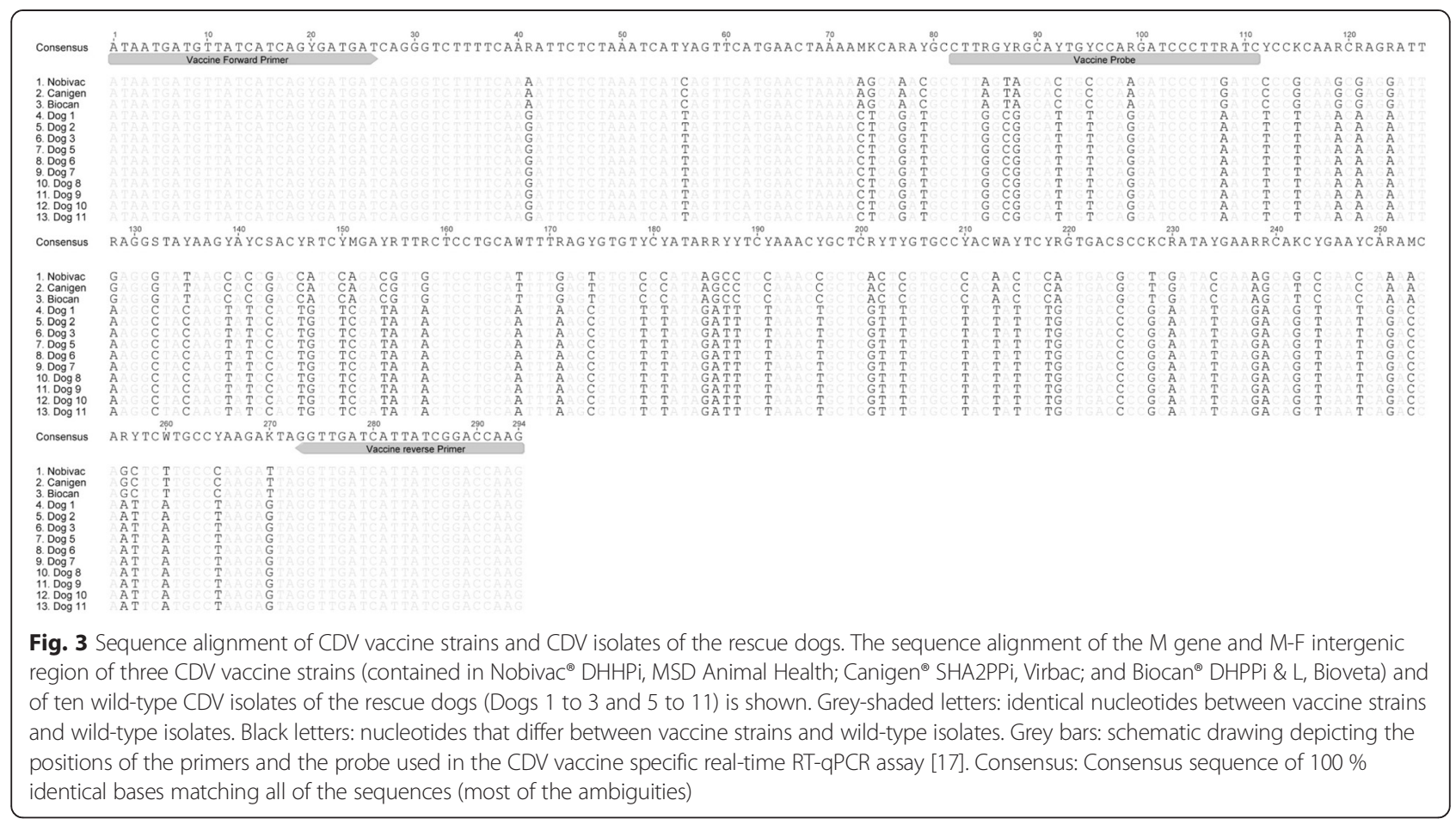

showed rapid clinical improvement with treatment and were discharged with oral antibiotic therapy. Repeated haematological examination in Dog 3 two weeks later revealed that the pancytopenia had resolved and had returned to moderate neutrophilia, eosinophilia and slight monocytosis. Mild anaemia was still present in Dog 3 at that time (data not shown). Repeated haematology in Dog 4 two weeks after the initial presentation showed normal platelets counts and nearly normal PCV values (data not shown). All three dogs were clinically asymptomatic in the 6-month follow-up period.

Dog 2 was ambulatory and was treated with oral antibiotics and antibiotic eye drops (Table 1). The dog showed several relapses with purulent nasal and ocular discharge after antibiotic therapy ceased and was repeatedly treated with antibiotics for two months. Thereafter, there was no relapse, and the dog was clinically asymptomatic in the remaining 4-month follow-up period.

Five CDV PCR-positive dogs (Dogs 5 to 8 and 10) received oral antibiotic therapy (amoxicillin clavulanic acid or doxycycline) for seven to ten days after their arrival in Switzerland. Dog 5 developed watery diarrhoea two weeks after arrival and was additionally treated with metronidazole, deworming and a highly digestible diet. Dog 8, which was co-infected with Babesia spp., received two injections of imidocarb diproprionate two weeks apart and antibiotic ear drops because of otitis externa. At the end of the 6-month follow-up period, all of the CDV PCR-positive dogs had recovered and none had developed neurological signs.

\section{Confinement of infection}

All of the owners of the CDV PCR-positive dogs were instructed by the first author (BW) to quarantine the dogs until they tested CDV PCR-negative. The owners of the CDV-positive dogs in multidog households (Dogs $3,6,7,8$ and 9) were instructed to separate the infected dog from the other dogs in the household. However, several dogs (Dogs 6, 7, 8 and 9) had already had contact with adult dogs within the household at the time when the CDV diagnosis was made. All of the contact dogs had been vaccinated against CDV, although several dogs had only received the initial vaccination series as puppies and had received no booster vaccinations (data not shown). Two dogs that were in close contact with Dogs 7 and 9 were tested for the CDV infection with PCR one month and two months after the initial CDV diagnosis in Dogs 7 and 9. One contact dog exhibited a single, very weak CDV-positive result in the conjunctival swab in the first sampling but was negative in all of the swabs collected one month later (data not shown). The other contact dog tested PCR-negative in all of the collected samples (data not shown). In all of the other multidog households, no samples were collected for CDV PCR, but no clinical signs of the disease were noted in the 6month follow-up period.

\section{Discussion}

The present study describes a distemper outbreak in rescue dogs in Switzerland that had been imported by an animal welfare organization. One dog had to be 


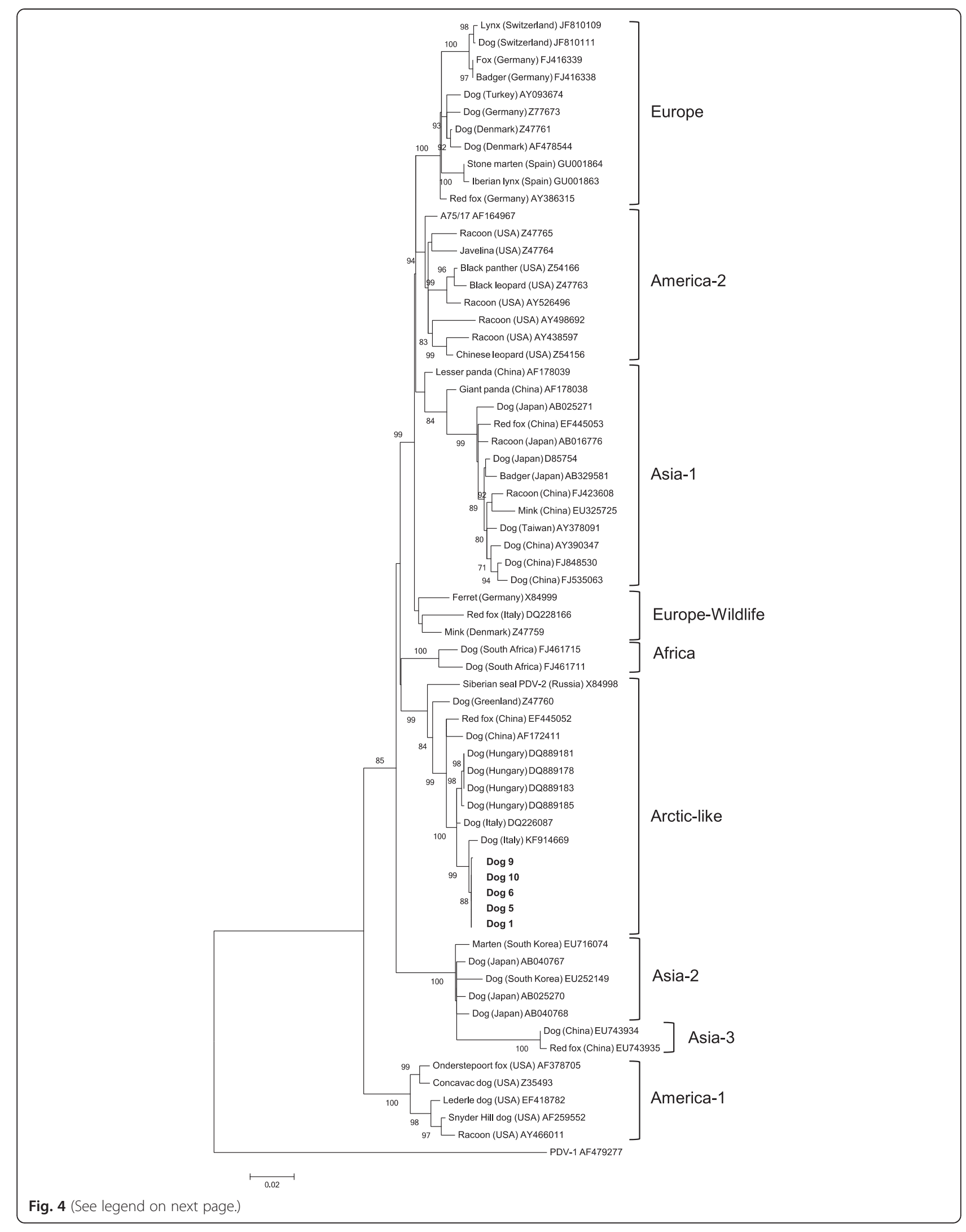


(See figure on previous page.)

Fig. 4 Phylogenetic relationship between selected CDV strains based on the complete haemagglutinin (HA) gene sequence. The CDV isolates analysed in this study appear in bold. Nine CDV lineages are shown: Asia-1, Europe, America-2, Europe-Wildlife, Africa, Arctic-like, Asia-2, Asia-3 and America-1. Phocine distemper virus (PDV-1) was used as the outgroup. GenBank accession numbers, host species and geographical origin are indicated, if known. The numbers at the nodes were generated from 1000 bootstrap resamplings; only values $>70$ are shown. The bar represents the mean number of differences per 200 sites. Strain AF178038 (giant panda isolate) is the resultant of a genetic recombination between "Asia-1" and a "Europe-Wildlife" strain [44]

euthanized directly after import for humane reasons, whereas nine dogs required therapy for up to two months; three of these dogs were hospitalized at veterinary clinics. The imported animals shed CDV for up to four months, which necessitated long-term quarantine measures. Moreover, four of the dogs were infected with vector-borne pathogens.

The present study underscores the risk of introducing contagious or vector-borne pathogens to central European countries by importing rescue dogs with incomplete vaccination. Based on the data of the ANIS in Switzerland, $43.9 \%$ of the newly registered dogs in 2012 were imported [16]. The imported dogs primarily comprised small and miniature purebred dogs to meet the increasing demand for these types of breeds in Switzerland, and mixed breed dogs that are rescued by animal welfare organisations [16]. The dogs of both groups are at risk for carrying infectious diseases because of the inadequate vaccination policies and quarantine measures in many breeding kennels and animal shelters in Eastern Europe. In the animal shelter in Hungary where the dogs originate, no quarantine measures or reliable vaccination policies had been implemented. The dogs had only received a single CDV vaccination either one week or one month before importation to Switzerland. At this time point, several dogs had likely been infected with CDV. After the outbreak, the rescue organisation was instructed to introduce vaccination policies and quarantine measures within the animal shelter.

In Switzerland, the vaccination rate in dogs is insufficiently high to provide population immunity against the CDV infection. The proportion of vaccinated dogs in a population must be $>70 \%$ to provide protection for the dog population, in contrast to protection of only a single vaccinated $\operatorname{dog}$ [19]. A vaccination rate of $60-70 \%$ has been estimated for Swiss dogs based on the numbers of sold vaccine doses in 2009 [20]. Mandatory courses for new dog owners have been introduced in Switzerland in which freshly adopted dogs come in close contact with each other. Together with the decreasing vaccination rate and the increasing number of imported dogs, this situation has clearly increased the risk for canine distemper outbreaks. Dog owners and animal welfare organisations should be informed concerning the critical importance of complete vaccination schedules in domestic dogs. In the present outbreak, the infection could be prevented from spreading to other dogs by extensive followup examinations of the dogs and a thorough education of the dog owners concerning the critical importance of strict quarantine measures. Luckily, no CDV-positive dogs of this study had already had contact with young unvaccinated dogs at the time of diagnosis. The CDV vaccines are known to induce a strong and long-lasting immunity when no interference with maternally derived antibodies occurs [21, 22].

CDV was reported to be shed by infected animals for up to three months $[11,23]$. We demonstrated CDV shedding in some dogs in the present study even for up to four months. Shedding was detected for several months after the cessation of clinical disease. Our results underscore the role of asymptomatic carriers in CDV epidemiology and the importance of a long-term followup of CDV-positive dogs for preventing the spread of infection. Several studies have reported the excretion of vaccine strains after CDV vaccination [11, 24]. This was not observed in the present study: the dogs that tested CDV PCR-positive were shown to be infected with wildtype CDV, although the majority of the dogs had received MLV CDV vaccination within one to seven weeks before PCR testing. Consistent with the published data [25], PCR from conjunctival swabs was found to be most reliable for detecting CDV in acutely infected animals and during follow-up examinations. However, in one animal, only the nasal but not the conjunctival swab tested positive for CDV.

Nine of the dogs in the present study were hospitalized or required ambulatory therapy for up to two months. Another animal was euthanised directly after import because of clinical deterioration. In all of the affected dogs, the respiratory and gastrointestinal symptoms predominated. In four dogs, signs of bronchopneumonia were evident. Remarkably, none of the dogs developed a neurological disease. Whether the latter was due to the intrinsic properties of the CDV strain or to the age and immune status of the dogs is unknown. The sequence analyses of the CDV strains detected in the rescue dogs indicated that all of the dogs were infected with the same wild-type CDV strain, which belongs to the Arctic-like lineage of CDV $[18,26]$. The initial description of Arctic-like lineage of CDV dates back to the late 1980s, when epizootics were observed in seals in Northern Europe and Siberia [27-29]. 
The strains of the Arctic-like lineage are closely related to the CDV strains in North America, China and Greenland and were recently isolated from domestic dogs in Hungary [30] and domestic dogs and wolves in Southern Italy $[31,32]$. The present study shows how fast these strains can spread to central European countries by import of infected domestic dogs.

The present study indicates that rescue dogs may also play an important role in the spread of vector-borne infections to central European countries. Babesia spp., L. infantum or D. immitis infections were detected in four of the 13 rescue dogs. Several dogs were reported to be free of these pathogens based on the laboratory certificates provided by the animal welfare organisation. In the case of Dog 13, D. immitis infection was diagnosed in this study using the antigen enzyme immunoassay and the Knott test in November 2013. The dog was found to be negative in the Knott test in August 2013. The $D$. immitis antigen and Knott tests are known to turn positive not before five to eight months after infection [33]; therefore, the infection could have been missed in the first testing. L. infantum serology specimen, which was positive in Dog 4, has similar limitations in that negative serological results cannot exclude infection and seroconversion can occur many months after infection [34]. Future dog owners should be properly informed concerning the limitations of these tests and the costs of treatment for vector-borne infections.

\section{Conclusion}

The present study highlights the risks of spreading contagious viral and vector-borne infections by a nonselective import of sick and unvaccinated dogs or dogs with incomplete vaccination from Eastern European countries. The animal welfare organisations should be thoroughly informed concerning the critical importance of complete vaccination schedules and quarantine measures in animal shelters to combat the outbreaks and the spread of viral pathogens to other countries. Dog owners in Switzerland should be educated regarding the risk of and the potential costs of adopting sick dogs or dogs with incomplete vaccination and the critical importance of sufficiently high vaccination rates in domestic dogs in Switzerland.

\section{Methods}

\section{Study design}

The present study describes a distemper outbreak in fifteen dogs originating from an animal shelter in Kecskemét, Hungary, and the prospective follow-up of the infected animals. The dogs were imported to Switzerland by an animal welfare organisation on October 22, 2013. One dog had to be euthanised within a several days of arrival. No data on that dog were available. Of the remaining fourteen dogs, the signalment, vaccination and medical history and clinical signs were recorded (Table 1) and dogs were monitored for six months.

\section{Sample and data collection and sample processing}

Within three weeks of arrival, a clinical examination was performed in 13 of the 14 dogs at the small animal clinics of the Vetsuisse Faculty, University of Zurich (Dogs 1 and 2) or Bern (Dog 3), by a private veterinarian (Dogs 4, 8 and 12) or by the first author (BW) during a visit of the dogs at their private homes (Dogs 5 to 7, 9 to 11 and 13, Table 1). No clinical examination or sample collection was possible in Dog 14 because of aggressive behaviour. In five dogs (Dogs 1 to 4 and 13), radiographic examinations of the thorax were performed at the small animal clinic of the Vetsuisse Faculty of Zurich (Dogs 1, 2 and 13), of the Vetsuisse Faculty of Bern (Dog $3)$, or by a private veterinarian (Dog 4). In Dog 13, echocardiography was performed at the division of cardiology, Vetsuisse Faculty, University of Zurich.

Nasal and/or conjunctival swabs were collected from 13 dogs for CDV-specific real-time RT-qPCR and rectal swabs from 12 dogs for CPV real-time qPCR as indicated in Tables 4 and 5. EDTA blood and serum samples were collected to obtain haematology and blood biochemistry results, and for CDV real-time RT-qPCR and testing for vector-borne infections (Babesia spp., E. canis, L. infantum and D. immitis) as indicated in Tables 2 through 5 . All of the samples were processed within $12 \mathrm{~h}$ of collection. In 10 of the $11 \mathrm{CDV}$-infected dogs (Dogs 1 to 3 and 5 to 11), monthly follow-up examinations for CDV were performed from conjunctival, nasal and oropharyngeal swabs (Table 4). The swabs were collected by the owner based on written and image instructions regarding how to collect and ship the samples. All of the swabs were sent by priority mail to the Clinical Laboratory, Vetsuisse Faculty, University of Zurich, within one day of collection. Follow-up was continued in each dog until the dog tested CDV PCRnegative, except for Dog 10, in which the owner declined further testing despite a PCR-positive result at three months of follow-up.

\section{Haematology and blood biochemistry}

Haematology and blood biochemistry tests were performed at the Clinical Laboratory, Vetsuisse Faculty, University of Zurich (Dogs 1 and 2, 5 to 11 and 13), at the Clinical Diagnostic Laboratory, Vetsuisse Faculty, University of Bern (Dog 3), at a private laboratory (Dog 4: Alomed, Radolfzell-Böhringen, Germany) or by a private veterinarian (Dog 8, Tables 2 and 3 ). The laboratory's own device-specific reference intervals were applied; for dogs aged 6 to 8 months (Dogs 2, 5 to 7), 
published reference intervals for phosphorous, alkaline phosphatase, urea and creatinine were used [35].

\section{Total nucleic acid (TNA) extraction}

At the time of the initial examinations, conjunctival, nasal or rectal swabs were incubated for $10 \mathrm{~min}$ in $300 \mu \mathrm{l}$ of phosphate buffered saline (PBS) at $40{ }^{\circ} \mathrm{C}$; the swabs were subsequently turned upside down and centrifuged for $1 \mathrm{~min}$ at $6440 \times g$ and the supernatant was used for TNA extraction (see below). For the follow-up examinations, the two conjunctival and the two nasal swabs, respectively, were pooled in a total of $400 \mu \mathrm{l}$ of PBS before incubation at $40{ }^{\circ} \mathrm{C}$ for $10 \mathrm{~min}$ and TNA extraction. The TNA extraction was performed from $100 \mu \mathrm{l}$ of EDTA blood, $200 \mu \mathrm{l}$ of swab supernatant or vaccine material that was resuspended in $500 \mu \mathrm{l}$ of PBS (see below) using the MagNa Pure LC (Roche Diagnostics AG, Rotkreuz, Switzerland) and the MagNa Pure LC TNA Isolation Kit (Roche Diagnostics) following the manufacturer's instructions. With each batch of extraction, a negative control consisting of $200 \mu \mathrm{l}$ of PBS was used to monitor for cross-contamination. The TNA was stored at $-80{ }^{\circ} \mathrm{C}$ until PCR analysis was performed.

\section{PCR assays and sequencing}

For CDV testing, a published real-time RT-qPCR assay was used as previously described [36]. For the detection of $\mathrm{CPV}$, a published real-time qPCR assay developed for the detection of feline parvovirus (FPV) was applied [37]. The assay amplifies a $107 \mathrm{bp}$ sequence of the highly conserved VP1/VP2 gene region using the following primers and probe: PV3294f: $5^{\prime}$-ACTGCATCATTGAT GGTTGCA-3'; PV3400r: 5'-GGTATGGTTGGTTTC CATGGA-3' PV3375p: 5'-FAM-CCCAATGTCTCAGA TCTCATAGCTGCTGG-6-TAMRA-3'. Sequence comparison revealed that the primer and probe-binding sites in the VP1/VP2 gene region of FPV and CPV showed > $99 \%$ sequence identity (GenBank accession numbers M38246, M38245, M19296, M74849, M74852, M24000, M24003, KM457142, JQ268284). During CDV follow-up, a published canine (c)GAPDH PCR assay was applied to ensure that the quality of the swabs collected by the dog owners was adequate [38]. During follow-up, dogs were stated CDV-negative if they tested PCR-negative for CDV in conjunctival, nasal and oropharyngeal swabs and the swabs showed a cGAPDH threshold cycle below 32. All of the real-time PCR reactions were run using an ABI 7500Fast Real-Time PCR system (Applied Biosystems, Rotkreuz, Switzerland). Negative and positive controls were included in each PCR run.

To ensure that the CDV real-time RT-qPCR signal was due to infection and was not due to a recent vaccination, a published real-time RT-qPCR system based on the CDV $\mathrm{M}$ gene and M-F intergenic region was used
[17]. The primers of the PCR assay amplify the MLV vaccine and wild type CDV strains, whereas the probe of the assay only binds to the MLV vaccine strains (Fig. 3). Because no sequence data have been published on the $\mathrm{M}$ gene and the M-F intergenic region of CDV U39 strain contained in the vaccine used in the rescue dogs (Biocan ${ }^{\bullet}$ DHPPi \& L, Bioveta), the latter vaccine, together with two other CDV vaccines that are commercially available in Switzerland (Nobivac ${ }^{\circ}$ DHHPi, MSD Animal Health; Canigen SHA2PPi, Vibac) were tested to confirm that the CDV strains contained in these vaccines are detected by the assay. The TNA from the three vaccines and from the conjunctival or nasal swabs from 10 of 11 CDV PCR-positive dogs (Dogs 1 to 3 and 5 to 11 ) were subjected to real-time RTqPCR. The PCR products were separated using $2.5 \%$ agarose gel and appropriate-sized bands (294 bp) cut out, extracted using the MinElute ${ }^{\bullet}$ Gel extraction kit (Qiagen, Hombrechtikon, Switzerland) and sequenced (Microsynth, Balgach, Switzerland).

The complete haemagglutinin (HA) genes of the CDV isolates from five dogs were sequenced (Dogs 1, 5, 6, 9 and 10). The TNA extracted from the conjunctival swabs was used as a template. For amplification, five previously published primer pairs were used [39]; single nucleotides in one primer pair ( $472 \mathrm{f}$ and $1172 \mathrm{r}$ ) had to be changed because of mismatches within the primer binding sites for the five CDV isolates (472f_new: 5'- CTGTACAT CACCAAGTCATA-3' and 1172r_new: 5'-TAGAATAC CATCTTGTGAAT-3'). Reverse transcription was performed using the High Capacity cDNA reverse transcription kit (Applied Biosystems) according to the manufacturer's instructions. The PCR amplification was conducted using $5 \mu \mathrm{l}$ of $5 \mathrm{x}$ HF PCR buffer (Finnzymes, BioConcept, Allschwil, Switzerland), $500 \mathrm{nM}$ each primer, $200 \mu \mathrm{M}$ each dNTP (Sigma-Aldrich, Buchs, Switzerland), 1 U Phusion High-Fidelity DNA Polymerase (Finnzymes), and $2.5 \mu \mathrm{l}$ template cDNA made up to $25 \mu \mathrm{l}$ with water. The thermal cycling conditions comprised $98{ }^{\circ} \mathrm{C}$ for $2 \mathrm{~min}, 35$ cycles at $98{ }^{\circ} \mathrm{C}$ for $30 \mathrm{~s}, 50{ }^{\circ} \mathrm{C}$ for $30 \mathrm{~s}, 65^{\circ} \mathrm{C}$ for $1 \mathrm{~min}$, and a final elongation at $72{ }^{\circ} \mathrm{C}$ for $3 \mathrm{~min}$. After the PCR run, the amplification products were separated using $2 \%$ agarose gel; appropriately sized products were excised and purified using the MinElute Gel Extraction Kit (Qiagen). Direct sequencing of the purified amplicons was performed using the amplification primers in a commercial laboratory (Microsynth, Balgach, Switzerland) under standard conditions.

\section{Testing for vector-borne infections}

Vector-borne infections were tested in 13 dogs, as shown in Table 5 . The analyses were performed at the Clinical Laboratory (for E. canis) and the Institute of Parasitology (for Babesia spp., L. infantum and D. immitis) 
of the Vetsuisse Faculty, University of Zurich, and at private laboratories (Dog 8: Labor am Zugersee, Hünenberg, Switzerland; Dog 4: Alomed; Dog 12: IDEXX Diavet AG, Bäch, Switzerland) (Table 5). The laboratories' own reference values were used for defining the positive, negative and intermediate results. The microscopic blood smear evaluation for the presence of Babesia spp. organisms was conducted in Dog 3 by the private veterinarian and in Dog 4 by a commercial laboratory (Alomed) (Table 5 ).

\section{Sequence editing and phylogenetic analyses}

The obtained sequences were edited and aligned with a consensus sequence using Geneious Version 7.1.8 [40]. Only the nucleotides available for all of the included sequences (2005 nucleotides of the HA gene) were used to calculate the percent nucleotide identities and perform the phylogenetic analyses. For the phylogenetic analyses, the sequences were aligned with known distemper sequences from GenBank (see Fig. 4) using Geneious Version 7.1.8. A bootstrap phylogenetic tree demonstrating the relationship between the isolates was created using the maximum-likelihood method [41] and a distance matrix corrected for nucleotide substitutions based on the Kimura 2-parameter model [42]. The dataset was resampled 1000 times to generate bootstrap values. The phylogenetic and molecular evolutionary analyses were conducted using the MEGA version 6 [43].

\section{Nucleotide sequence accession numbers}

Nucleotide sequences obtained in this study have been submitted to GenBank under accession numbers KR002657 to KR002671.

\section{Abbreviations \\ CDV: Canine distemper virus; MLV: Modified live virus; ANIS: Animal identity service; CPV: Canine parvovirus; RT: Reverse transcription; q: Quantitative; TNA: Total nucleic acid; PBS: Phosphate buffered saline; FPV: Feline parvovirus; c: Canine; HA: Haemagglutinin; PDV: Phocine distemper virus.}

\section{Competing interests}

The authors declare that they have no potential conflicts of interest to disclose.

\section{Authors' contributions}

$\mathrm{RHL}$ and BW conceived the study. BW and AMS were responsible for the study coordination and the data and sample collections. LB, TB and RJ were responsible for the clinical work-up and medical care of the dogs. MLM was responsible for the molecular laboratory aspects, FG was responsible for the analyses of vector-borne infections, BR was responsible for the haematology and blood biochemistry tests and MD was responsible for all aspects of diagnostic imaging. $\mathrm{RHL}$ and BW drafted the manuscript. All of the authors read and approved the final manuscript.

\section{Acknowledgements}

The authors thank the animal rescue organisation and the owners of the dogs for providing the data and supporting diagnostic work-up. We thank T. Meili, E. Goenczi, S. Childers and the technicians of the Clinical Laboratory for their excellent laboratory assistance. The laboratory work was performed using the logistics of the Center for Clinical Studies, Vetsuisse Faculty, University of Zurich. AS was supported by a research grant (Forschungskredit, FK53210-01-01) from the University of Zurich.

\section{Author details}

${ }^{1}$ Clinical Laboratory, Vetsuisse Faculty, University of Zurich, Zurich, Switzerland. ${ }^{2}$ Center for Clinical Studies, Vetsuisse Faculty, University of Zurich, Zurich, Switzerland. ${ }^{3}$ Clinic for Small Animal Internal Medicine, Vetsuisse Faculty, University of Zurich, Zurich, Switzerland. ${ }^{4}$ Institute of Parasitology, Vetsuisse Faculty, University of Zurich, Zurich, Switzerland. ${ }^{5}$ Clinic of Diagnostic Imaging, Vetsuisse Faculty, University of Zurich, Zurich, Switzerland. ${ }^{6}$ Kleintierpraxis Dres. med. vet. Rohner \& Bley, Niederglatt, Switzerland. ${ }^{7}$ Kleintierpraxis Dr. med. vet. Rolf Jordi, Gümligen, Switzerland.

Received: 25 March 2015 Accepted: 7 July 2015

Published online: 16 July 2015

\section{References}

1. Kapil S, Yeary TJ. Canine distemper spillover in domestic dogs from urban wildlife. Vet Clin North Am Small Anim Pract. 2011;41(6):1069-86. doi:10.1016/j.cvsm.2011.08.005.

2. Deem SL, Spelman LH, Yates RA, Montali RJ. Canine distemper in terrestrial carnivores: a review. J Zoo Wildl Med. 2000;31(4):441-51.

3. Harder TC, Osterhaus AD. Canine distemper virus - a morbillivirus in search of new hosts? Trends Microbiol. 1997;5(3):120-4. doi:10.1016/S0966842X(97)01010-X.

4. Cleaveland S, Appel MG, Chalmers WS, Chillingworth C, Kaare M, Dye C. Serological and demographic evidence for domestic dogs as a source of canine distemper virus infection for Serengeti wildlife. Vet Microbiol. 2000;72(3-4):217-27.

5. Appel MJ. Pathogenesis of canine distemper. Am J Vet Res. 1969;30(7):1167-82.

6. Watanabe $\mathrm{Y}$, Miyata $\mathrm{H}$, Sato $\mathrm{H}$. Inactivation of laboratory animal RNA-viruses by physicochemical treatment. Jikken Dobutsu. 1989;38(4):305-11.

7. Appel MJ, Shek WR, Summers BA. Lymphocyte-mediated immune cytotoxicity in dogs infected with virulent canine distemper virus. Infect Immun. 1982;37(2):592-600.

8. Martella V, Elia G, Buonavoglia C. Canine distemper virus. Vet Clin North Am Small Anim Pract. 2008;38(4):787-97. doi:10.1016/j.cvsm.2008.02.007. vii-viii.

9. Rudd PA, Cattaneo R, von Messling V. Canine distemper virus uses both the anterograde and the hematogenous pathway for neuroinvasion. J Virol. 2006:80(19):9361-70. doi:10.1128/JVI.01034-06.

10. Rudd PA, Bastien-Hamel LE, von Messling V. Acute canine distemper encephalitis is associated with rapid neuronal loss and local immune activation. J Gen Virol. 2010;91(Pt 4):980-9. doi:10.1099/vir.0.017780-0.

11. Greene CE, Vandevelde M. Canine Distemper. Infectious Diseases of the Dog and Cat. 4th ed. 2012. p. 25-42.

12. Tipold A, Vandevelde M, Jaggy A. Neurological manifestations of canine distemper virus infection. J Small Anim Pract. 1992;33(10):463-512

13. Green RG, Swale FS. Vaccination of dogs with modified distemper virus. J Am Vet Med Assoc. 1939:95:469-70.

14. Glardon O, Stockli R. Distemper epidemic in Switzerland: epidemiology and anamnesis of vaccination. Schweiz Arch Tierheilkd. 1985;127(11):707-16.

15. Origgi FC, Plattet $P$, Sattler U, Robert N, Casaubon J, Mavrot F, et al. Emergence of canine distemper virus strains with modified molecular signature and enhanced neuronal tropism leading to high mortality in wild carnivores. Vet Pathol. 2012;49(6):913-29. doi:10.1177/0300985812436743.

16. Animal Identity Service (ANIS), Switzerland. Geschäftsbericht 2012. http:// www.anis.ch/uploads/media/Geschaeftsbericht_2012.pdf.

17. Wilkes RP, Sanchez E, Riley MC, Kennedy MA. Real-time reverse transcription polymerase chain reaction method for detection of Canine distemper virus modified live vaccine shedding for differentiation from infection with wild-type strains. J Vet Diagn Invest. 2014;26(1):27-34. doi:10.1177/ 1040638713517232.

18. Marcacci M, Ancora M, Mangone I, Teodori L, Di Sabatino D, De Massis F, et al. Whole genome sequence analysis of the arctic-lineage strain responsible for distemper in Italian wolves and dogs through a fast and robust next generation sequencing protocol. J Virol Methods. 2014;202:64-8. doi:10.1016/j.jviromet.2014.02.027.

19. Horzinek MC. Vaccine use and disease prevalence in dogs and cats. Vet Microbiol. 2006;117(1):2-8. doi:10.1016/j.vetmic.2006.04.002.

20. Gesellschaft Schweizer Tierärztinnen und Tierärzte (GST) und Schweizerische Vereinigung für Kleintiermedizin (SVK). Geliebt! Geimpft? http:// www.geliebtgeimpft.ch. 2009 . 
21. Roth JA, Spickler AR. Duration of immunity induced by companion animal vaccines. Anim Health Res Rev. 2010;11(2):165-90. doi:10.1017/ S1466252310000150

22. Schultz RD, Thiel B, Mukhtar E, Sharp P, Larson LJ. Age and long-term protective immunity in dogs and cats. J Comp Pathol. 2010;142 Suppl 1:S102-8. doi:10.1016/j.jcpa.2009.10.009.

23. Elia G, Decaro N, Martella V, Cirone F, Lucente MS, Lorusso E, et al. Detection of canine distemper virus in dogs by real-time RT-PCR. J Virol Methods. 2006;136(1-2):171-6. doi:10.1016/j.jviromet.2006.05.004.

24. Jozwik A, Frymus T. Comparison of the immunofluorescence assay with RT-PCR and nested PCR in the diagnosis of canine distemper. Vet Res Commun. 2005;29(4):347-59.

25. Kim D, Jeoung SY, Ahn SJ, Lee JH, Pak SI, Kwon HM. Comparison of tissue and fluid samples for the early detection of canine distemper virus in experimentally infected dogs. J Vet Med Sci. 2006;68(8):877-9.

26. Balboni A, De Lorenzo Dandola G, Scagliarini A, Prosperi S, Battilani M. Occurrence of different Canine distemper virus lineages in Italian dogs. Vet Ital. 2014;50(3):227-31. doi:10.12834/Netlt.52.2173.2.

27. Osterhaus A, Broeders H, Spijkers H, Groen J, Vedder E. An outbreak of dog distemper among seals (2). Tijdschr Diergeneeskd. 1988;113(19):1061-2.

28. Likhoshway Ye V, Grachev MA, Kumarev VP, Solodun Yu V, Goldberg OA Belykh Ol, et al. Baikal seal virus. Nature. 1989;339(6222):266. doi:10.1038/ $339266 a 0$.

29. Visser IK, Kumarev VP, Orvell C, de Vries P, Broeders HW, van de Bildt MW, et al. Comparison of two morbilliviruses isolated from seals during outbreaks of distemper in north west Europe and Siberia. Arch Virol. 1990;111(34):149-64

30. Demeter Z, Lakatos B, Palade EA, Kozma T, Forgach P, Rusvai M. Genetic diversity of Hungarian canine distemper virus strains. Vet Microbiol. 2007;122(3-4):258-69. doi:10.1016/j.vetmic.2007.02.001

31. Martella V, Cirone F, Elia G, Lorusso E, Decaro N, Campolo M, et al. Heterogeneity within the hemagglutinin genes of canine distemper virus (CDV) strains detected in Italy. Vet Microbiol. 2006;116(4):301-9. doi:10.1016/ j.vetmic.2006.04.019.

32. Di Sabatino D, Lorusso A, Di Francesco CE, Gentile L, Di Pirro V, Bellacicco $\mathrm{AL}$, et al. Arctic lineage-canine distemper virus as a cause of death in Apennine wolves (Canis lupus) in Italy. PLoS One. 2014;9(1):e82356. doi:10.1371/journal.pone.0082356.

33. Hoch H, Strickland K. Canine and feline dirofilariasis: life cycle, pathophysiology, and diagnosis. Compend Contin Educ Vet. 2008;30(3):133-40. quiz 41

34. Paltrinieri S, Solano-Gallego L, Fondati A, Lubas G, Gradoni L, Castagnaro M, et al. Guidelines for diagnosis and clinical classification of leishmaniasis in dogs. J Am Vet Med Assoc. 2010;236(11):1184-91. doi:10.2460/ javma.236.11.1184

35. von Dehn B. Pediatric clinical pathology. Vet Clin North Am Small Anim Pract. 2014:44(2):205-19. doi:10.1016/j.cvsm.2013.10.003.

36. Meli ML, Cattori V, Martinez F, Lopez G, Vargas A, Simon MA, et al. Feline leukemia virus and other pathogens as important threats to the survival of the critically endangered Iberian lynx (Lynx pardinus). PLoS One. 2009;4(3):e4744. doi:10.1371/journal.pone.0004744.

37. Meli M, Kipar A, Muller C, Jenal K, Gonczi E, Borel N, et al. High viral loads despite absence of clinical and pathological findings in cats experimentally infected with feline coronavirus (FCoV) type I and in naturally FCoV-infected cats. J Feline Med Surg. 2004;6(2):69-81. doi:10.1016/j.jfms.2003.08.007.

38. Sieber-Ruckstuhl NS, Meli ML, Boretti FS, Gonczi E, Lutz H, Reusch CE. Quantitative real-time PCR for the measurement of 11 beta-HSD1 and 11 beta-HSD2 mRNA levels in tissues of healthy dogs. Horm Metab Res. 2007:39(8):548-54. doi:10.1055/s-2007-985142.

39. Sekulin K, Hafner-Marx A, Kolodziejek J, Janik D, Schmidt P, Nowotny $N$. Emergence of canine distemper in Bavarian wildlife associated with a specific amino acid exchange in the haemagglutinin protein. Vet J. 2011;187(3):399-401. doi:10.1016/j.tvjl.2009.12.029.

40. Kearse M, Moir R, Wilson A, Stones-Havas S, Cheung M, Sturrock S, et al. Geneious Basic: an integrated and extendable desktop software platform for the organization and analysis of sequence data. Bioinformatics. 2012;28(12):1647-9. doi:10.1093/bioinformatics/bts199.

41. Tamura K, Nei M, Kumar S. Prospects for inferring very large phylogenies by using the neighbor-joining method. Proc Natl Acad Sci U S A. 2004:101(30):11030-5. doi:10.1073/pnas.0404206101.
42. Kimura M. A simple method for estimating evolutionary rates of base substitutions through comparative studies of nucleotide sequences. J Mol Evol. 1980;16(2):111-20

43. Tamura K, Stecher G, Peterson D, Filipski A, Kumar S. MEGA6: Molecular Evolutionary Genetics Analysis version 6.0. Mol Biol Evol. 2013;30(12):2725-9. doi:10.1093/molbev/mst197.

44. Han GZ, Liu XP, Li SS. Cross-species recombination in the haemagglutinin gene of canine distemper virus. Virus Res. 2008;136(1-2):198-201. doi:10.1016/j.virusres.2008.04.022.

45. Mettler M, Grimm F, Capelli G, Camp H, Deplazes P. Evaluation of enzyme-linked immunosorbent assays, an immunofluorescent-antibody test, and two rapid tests (immunochromatographic-dipstick and gel tests) for serological diagnosis of symptomatic and asymptomatic Leishmania infections in dogs. J Clin Microbiol. 2005;43(11):5515-9. doi:10.1128/ JCM.43.11.5515-5519.2005.

46. Magnis J, Lorentz S, Guardone L, Grimm F, Magi M, Naucke TJ, et al. Morphometric analyses of canine blood microfilariae isolated by the Knott's test enables Dirofilaria immitis and D. repens species-specific and Acanthocheilonema (syn. Dipetalonema) genus-specific diagnosis. Parasit Vectors. 2013;6:48. doi:10.1186/1756-3305-6-48.

\section{Submit your next manuscript to BioMed Central and take full advantage of:}

- Convenient online submission

- Thorough peer review

- No space constraints or color figure charges

- Immediate publication on acceptance

- Inclusion in PubMed, CAS, Scopus and Google Scholar

- Research which is freely available for redistribution 